\title{
THE USE OF DISCOURSE MARKERS AS AN INTERACTIVE FEATURE IN SCIENCE LECTURE DISCOURSE IN L2 SETTING
}

\author{
Akhyar Rido \\ (rido3782@yahoo.com) \\ STBA Teknokrat Lampung, Indonesia
}

\begin{abstract}
The objective of this research is to investigate the function of discourse markers as an interpersonal-interactive feature in a science lecture in second language (L2) setting in Malaysia. This research employs qualitative method while the data are gathered through non-participant observation and videorecording. From the findings, there are various discourse markers found. Macro markers signal the transition of the moves and indicate a shift of one topic/subtopic to another topic/sub-topic. Meanwhile, micro markers signal the internal or ideational relations within sentences. In conclusion, the use of discourse markers will help students to comprehend a lecture.
\end{abstract}

Key words: discourse markers, science lecture, L2 setting

This research is aimed to investigate the function of discourse markers as an interpersonal-interactive feature in a science lecture in second language (L2) setting in Malaysia where English is used as the medium of instruction in tertiary level, especially in the faculty of sciences and technology. Studies on Non-Native Speakers (NNS) of English students (Chaudron and Richards 1986; Olsen and Huckin 1990; Flowerdew and Miller 1996; Young 1994) indicate that second language (L2) listeners often have difficulties in following the structure of a text for a substance of comprehension, even though sometimes they have no lexical obstacles at all. This brings to a suggestion that knowledge of the linguistic/discoursal structure is necessarily needed by both lecturers and students because it will be of value for lecturers to deliver a lecture in a well-structured and an optimally effective way. 
Interactive discourse structuring is used to guide listeners through ongoing speech and has been shown to have a positive effect on lecture comprehension, particularly in L2 settings. Yang (2007: 25) examines the effects of discourse signaling cues on L2 listening comprehension. Eighty Korean EFL learners took part in this study. One half listened to the lecture with signaling cues, while another half listened to the lecture without signaling cues. The findings show that signaled group performed significantly better than non-signaled group in both macro and micro information comprehension.

As mobility increases in the academic world, there are more possibilities for lecture events characterized not only by linguistic/cultural diversity but also by unfamiliarity between lecturers and audiences (Camiciottoli, 2004: 41). In this situation, interactive discourse structuring may have an especially important role in terms of improving students' linguistic and communicative competence also establishing a comfortable context that will encourage participation (Morell, 2000; Camicciottoli, 2004).

It is important to understand discourse markers since they are part of the more general analysis of discourse coherence-how speakers and hearers integrate forms, meanings, and actions to make overall sense out of what is said (Schiffrin 1987: 49). Further, they are regarded as cohesive devices which reflect underlying connection between propositions-connections that are inferred by producers and interpreters of a text. They also add cohesion to a discourse. It has to do with semantic meaning (Schiffrin 1987: 61).

According to Chaudron and Richards (1986), discourse markers can be categorized into two: macro and micro. Macro markers mean higher-order markers signaling major transitions and emphasis in a lecture. In a lecture, macro markers are essentially used to signal the transition the moves from one phase of a lecture to another phase, to indicate a shifting of one topic to another topic, and to organize the lecture structurally so that students are clear about the subject matters. Meanwhile, micro markers are considered as lower-order markers of segmentations and inter-sentential connections. They are fundamentally used as links to signal the internal or ideational relations within sentences so the relations of one clause to another clause or one sentence to another sentence are easier to comprehend.

\section{METHOD}

This research employs purely qualitative method. In general, qualitative methods are subjective and humanistic as they deal with meanings. It is 
different from quantitative method which is regarded as more objective and scientific as they deal with numbers (Clarke and Dawson 1999: 38). Further, the data are gathered through two ways namely non-participant observation and video-recording.

The researcher conducted observations, as a non-participant observer, on 8 August and 12 September 2008 by directly observing two lecture sessions at the Faculty of Science and Technology in a university in Malaysia from the same lecturer. The first lecture (LE1) was about 'forces' while the second one (LE2) was about 'centre of mass'. The first lecture lasted approximately one and half hour, while the second lecture lasted approximately one hour. During the observation the researcher brought and used recording field notes. The researcher stayed in the lecture hall and observes everything from the very beginning until the very end of the lectures. Furthermore, in this research, the video recording process was also done on the same days of observation to collect data. A technician helped recording the two lectures. Then, the recordings were converted to DVD version and transcribed manually using a notebook and a headset. In transforming the video-recording into a transcribed form, the details of gestures, intonations, and postures during the lectures were also noted. Afterwards, the transcriptions were typed in Ms. Word program.

Participants, events, and setting are called as a series of vignettes (Flowerdew, 2002). Even though there are lecturer and students as participants, this study only focused on the lecturer. The lecturer is a professor of physics in the Faculty of Science and Technology. She has more than twenty-years teaching experiences and teaches both undergraduate and postgraduate courses. During her career, she participates in many teaching professional development programs, seminars, and workshops. Moreover, the event of this discourse is the two science lectures and part of physical mechanic course. The first lecture recorded discusses 'forces' while the second lecture concerns 'centre of mass'. Further, the setting of this lecture event is in a large lecture theatre which can accommodate approximately 200 students. The lecturer used microphone during the lecture and spoke from the front of the room, about 2 or 3 meters away from the first row of the students. Sometimes she walked around and approached the students. The lecture lasted approximately one to two hours.

\section{FINDINGS AND DISCUSSION}

Discourse markers are regarded as one of interpersonal interactive features in a lecture because they can show how a lecturer and students inte- 
grate forms, meanings, and actions (Schriffin 1987). This section will discuss the use of discourse markers in LE (1) and LE (2) and their functions as interpersonal interactive features. According to Chaudron and Richards (1986) discourse markers are divided into micro and macro. The discussion that follows will be in two parts. The first is on macro markers and the second on micro markers.

\section{Macro Markers}

In this section, the discussion is done based on classification of macro markers namely rephraser and topic shifter (Chaudron and Richards 1986). These markers are higher-order markers signaling major transitions and emphasis in a lecture. It can help students with the overall organization of a lecture as well as comprehending the functional intention of the speaker in relation to subsidiary parts of the lecture. Let us turn to the data and see the types of macro markers employed by the lecturer and to identify their function in the discourse.

\section{Rephraser}

The data show that three kinds of rephraser: that means, I mean, and which means to say that are identified. That means and which means to say that appear in both LE (1) and LE (2) while I mean only appears in LE (2)

\section{a) THAT MEANS}

The findings show that that means marker has been used as rephraser by the lecturer in both LE (1) and LE (2). That means marker is used 3 times in LE (1) and 3 times in LE (2). That means in line 71 of LE (1) functions to signal that the statement after the marker rephrases a term mentioned earlier. So, that means in line 74 refers to stationary and this is seen from the context of juxtaposing 'Escalator is moving but I am stationary' (line 71). This part can be seen in Data Sample 1 below.

Data Sample 1: LE (1)

\begin{tabular}{|l|l|l|}
\hline 71 & L & $\begin{array}{l}\text { (..) If the escalator is moving (.) but I am stationary. } \\
\text { (.) Understand, what is stationary there? (/) }\end{array}$ \\
\hline 73 & S & [instantaneous reply] yeah. \\
\hline 74 & L & That means I'm (/) not \\
\hline 75 & S & (.) moving \\
\hline
\end{tabular}

Further, that means in line 277 of Data Sample 2 of LE (2) below functions to signal that the statement after the marker rephrases a term 
mentioned earlier. In lines 277-279 the lecturer said, 'The work done is used to increase the kinetic energy and also the potential energy'. This statement actually refers to preceding statement 'So, the body increases the kinetic energy while the spring increases its potential energy' (lines 275277).

Data Sample 2: LE (2)

\begin{tabular}{|l|l|l|}
\hline 275 & L & the object:: as well as the spring. So, the body (..) increases \\
276 & & the kinetic energy while the spring increases its pot::ential \\
277 & & energy. So, that means the work done (..) is used to in- \\
278 & & crease the kinetic energy and also the potential energy. (..) \\
279 & & So, that is the principle of \\
\hline
\end{tabular}

Now we turn to I Mean

b) I MEAN

From both lectures I mean appears only once in LE (1) in line 397 in Data Sample 3 below this marker is used by the lecturer to refer revise her preceding statement. It is noted that she gives explanations about the use of graph to determine average speed and average acceleration (line 393). She, then, states that to change it into differential expressions are not just dy by $\mathrm{dx}$ but also dy by dt (lines 395-398). In this case, she was correcting herself.

\section{Data Sample 3: LE (1)}

\begin{tabular}{|l|l|}
\hline 388 & development of calculus (/).If you still remember, in the last \\
389 & 2 lectures we were: learning about (/) average speed, aver- \\
390 & age velocity, average acceleration. Yeah. And you move on \\
391 & to instantaneous (.) speed, instantaneous (.) acceleration. \\
392 & And I told you that, yes, (/) in terms of average speed, and \\
393 & average acceleration. you can make use of the graphs: to \\
394 & determine the x / dt or dv / dt and, how you move on (/) to \\
395 & change it into (.3) the differential expression dy by dx, ah.. I \\
396 & mean dy by dt or dx by dt (..) as well as dv by dt. Now all \\
397 & those, (...) will be related to, calculus. So, that is the other \\
398 & work that he has been doing. Now let’s see what is it (.5) \\
399 & just (.hh) keep on checking on that. [approaches students] \\
400 & (.5) How many of you (/) have been thinking about this? (/) \\
401 &
\end{tabular}

Let us now turn to which means to say that. 


\section{c) WHICH MEANS TO SAY THAT}

Which means to say that markers appear twice both in LE (1) and LE (2). In lines 591-592 the lecturer uses which means to say that in order to signal a rephrasing of the proposition preceding marker. Here, it refers to the meaning of calibrate in relations to the thermometer (lines 592-594). This part can be seen from Data Sample 4 below.

\section{Data Sample 4: LE (1)}

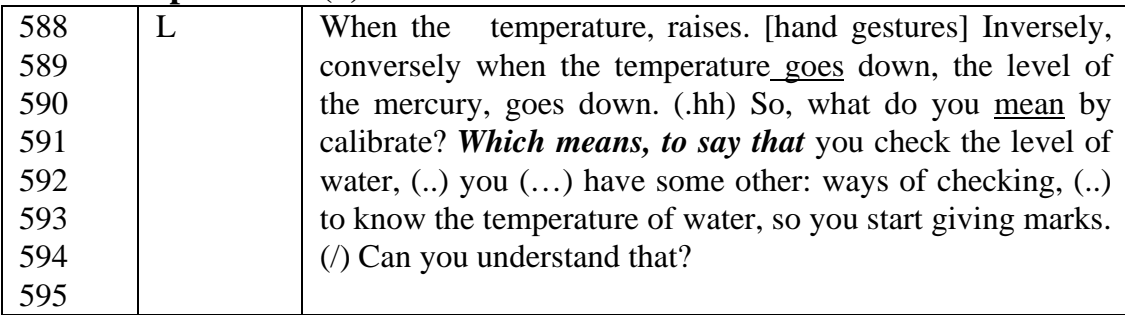

On the other hand, in Data Sample 5, which is rather long turn, the lecturer was trying to show the meaning of the position of centre (line 342) and she reformulated by saying that 'You need to have the point of reference or origin' (line 343).

\section{Data Sample 5: LE (2)}

\begin{tabular}{|l|l|l|}
\hline 332 & L & Ok, this is the centre of mass. [reprimands the student]. \\
333 & & Don't be shy. You are helping your friends to understand. \\
334 & ((laughter)). ok, this are just simple. Alright? (..) Centre of \\
335 & & mass. When you look in your book, there are just points \\
336 & & $\begin{array}{l}\text { (.hh). Can you have a look in your, where is it (/)? There } \\
\text { you are (.hh). page 203. that 2 blue dots. So, (..) if I were to }\end{array}$ \\
337 & & $\begin{array}{l}\text { take your friends, to represent (.) the particles or the points, } \\
\text { then you can have the impact, (.) the feeling is better, but }\end{array}$ \\
339 & & $\begin{array}{l}\text { how are you going to tell me the position of the centre:: of } \\
\text { mass (/). Which means to say that (.) you need to have the }\end{array}$ \\
340 & & (/) point of reference, the origin. Where are \\
342 & &
\end{tabular}

In Data Sample 6 below which means to say that marks a rephrasing of a series of exchanges. Here, there is a question in line 441 asking y coordinate and since the students' responses are correct in lines 445 and 451, she summarizes the answers and arrives at a conclusion. 
Data Sample 6: LE (2)

\begin{tabular}{|l|l|l|}
\hline 441 & L & $\begin{array}{l}\text { Y3. how bout you? [points to another student]. What is your } \\
\text { y coordinate? }\end{array}$ \\
\hline 443 & S & (.3)[Inaudible response] \\
\hline 444 & L & Can you (..) say it loud? \\
\hline 445 & S & Y2 \\
\hline 446 & L & Do you agree? (/) She is Y2? \\
\hline 447 & S & Yes::. \\
\hline 448 & L & Right. She is Y2. (..) How about you? \\
\hline 449 & S & (..) Inaudible response. \\
\hline 450 & L & Loud, loud, loud. \\
\hline 451 & S & Y3 \\
\hline 452 & L & $\begin{array}{l}\text { Y3. (.) So, which means to say that each and everyone of } \\
\text { the particles, have their own coordinate. }\end{array}$ \\
\hline
\end{tabular}

\section{Topic Shifter}

This section will present findings on the markers employed as topic shifts. There are three kinds of rephraser found in the lectures: so, now, and so anyway. So and now appear in both LE (1) and LE (2) while so anyway only appears in LE (2)

\section{a) $\mathrm{SO}$}

The findings show that the So- marker has been used as topic shift markers by the lecturer in both LE (1) and LE (2). So marker appears only once in LE (1) and twice in LE (2). In lines 273-294 of LE (1) the lecturer has a monologue, a long turn exploring the meaning of representation and she attempts to show the rationale of learning physics (a digression) (line 294). After that, the lecturer talks about forces-asking the students the meaning of forces for them (line 294). Here, so marks the shift (line 294). This part can be seen from Data Sample 7 below.

\section{Data Sample 7: LE (1)}

\begin{tabular}{|c|c|c|}
\hline $\begin{array}{l}273 \\
274 \\
275 \\
276 \\
277 \\
278 \\
279 \\
280\end{array}$ & $\mathrm{~L}$ & $\begin{array}{l}\text { Algebraic of:: mathematical, representation:: of physi::cal } \\
\text { phenomena's. And now, you have to understand that (.) and } \\
\text { this is what, you can carry right through, until you finish } \\
\text { your education, and you don't stop there and we can use it } \\
\text { over and over again. So, you can represent processes (/) of } \\
\text { physical phenomena diagrammatically, graphically and ma- } \\
\text { thematically and (..) so, that is what I asked, you to do last, } \\
\text { the last time. (..) I said, ok today you are going to solve }\end{array}$ \\
\hline
\end{tabular}




\begin{tabular}{|l|l|l|}
\hline \multicolumn{2}{|l|}{ Data continued } & \\
\hline 281 & & problems and show the linkage, between the initial (/) situa- \\
282 & & tion and final (hh) situation(..) and see what is happening \\
283 & & $(.5)$ and $(.4)$ can provide cause and effect reasons when ex- \\
284 & plaining physical phenomena, using various representation. \\
285 & Now all of this, [points to screen] (.9) provide cause \\
286 & and effect, reasons. (.5) In the past, we expect you to sort of \\
287 & know it like that. (..) But, (.4) [hand gestures] overtime we \\
288 & realized, that we cannot take it for grant:ed. We need to let \\
289 & students to develop, such abilities. How:: to explain. Can \\
290 & you (/) actually give the reasons why (/) things happen? \\
291 & What do you do? How do you go about it? So let’s see, what \\
292 & is going to happen next. Incidentally, what (/) is force for \\
293 & you? \\
294 & & \\
\hline
\end{tabular}

Further, in LE (2) the lecturer also uses So as topic shift marker. In Data Sample 8 below, in lines 538-554 of LE (1) the lecturer has a monologue, exploring how to find a centre of mass on solid body (lines 539-548). However, while she is exploring it she realizes that the students' seem to have no interest following the lecture. Suddenly she comments something not related to the topic of lecture called digression. She commented 'I see a number of you yawning. Yeah. You're bit sleepy’ (lines 550-551). Here, So marks a shift from the digression back to the main discussion on centre of mass (line 552). This is followed by an instruction by the lecturer to the students to look at their books and do the exercise (lines 553-554).

Data Sample 8: LE (2)

\begin{tabular}{|c|c|c|}
\hline $\begin{array}{l}538 \\
539 \\
540 \\
541 \\
542 \\
543 \\
544 \\
545 \\
546 \\
547 \\
548 \\
549 \\
550 \\
551\end{array}$ & $\mathrm{~L}$ & $\begin{array}{l}\text { Just now, (..) I was talking about particles, now this is solid } \\
\text { body. [shows the duster as an example]. You look at the } \\
\text { benches. The benches, you don't divide it right, but look at } \\
\text { the chairs, (..) } 1,2,3,4 \text {. (.4) so the benches you can regard it } \\
\text { as a whole body. How are you going to determine the centre } \\
\text { of mass for a solid? that means (..) it is not been split into } \\
\text { particles. This is a good example of particles. (..) But if all } \\
\text { of you get stuck together somehow, can glue all of you up, } \\
\text { cannot free yourself (..) than you become ( ) solid particle. } \\
\text { So, how do you that? You see the use of integration. Are } \\
\text { you with me (/)? Are you with me? [inaudible response } \\
\text { from students (yes)] I see a number (..) of you yawning. } \\
\text { Yeah. You're bit sleepy. So, look at } 99 \text {. (..) now, what does } \\
\text { that mean (/)? What is the meaning of DM (/)? can you tell }\end{array}$ \\
\hline
\end{tabular}




\begin{tabular}{|l|l|l|}
\hline \multicolumn{2}{|l|}{ Data continued } \\
\hline 552 & me what is the meaning of DM? ahh:: \\
553 & & \\
554 & & \\
\hline
\end{tabular}

We shall now turn to now marker.

\section{b) NOW}

The findings show that now at the beginning of a turn has been used as topic shift markers by the lecturer in both LE (1) and LE (2). In LE (1) now appears 6 times while in LE (2) it appears 3 times. In Data Sample 9 below now is used as a topic shift marker from velocity to category of forces (line 472).

Data Sample 9: LE (1)

\begin{tabular}{|l|l|l|}
\hline 467 & L & (..) but, what kind of acceleration? You call that, negative \\
468 & & acceleration:: or de:celebration (..) Ok, this is something \\
469 & & that you need to bear in mind and also there (.) you are. Is a \\
470 & & change in velocity the same as acceleration? explain your \\
471 & & answer. That, (.) I have to leave it to you (..) [moves back \\
472 & & onto podium] now, again here, there are two (.3) types of \\
473 & & forces. You all have been told about this in the past (..) but \\
474 & & to what extend, [hand gestures] you sort of categorize:.: the \\
475 & & forces, ok, here it says two types, [points 2 fingers](..) two \\
476 & & classes (/) of forces, (..) contact. Are you familiar \\
477 & &
\end{tabular}

In LE2, the lecturer also uses now as a topic shift marker. In Data Sample 10 below now is used to indicate an item shift from question number three to number six of the quiz (line 257).

\section{Data Sample 10: LE (2)}

\begin{tabular}{|l|l|l|}
\hline 252 & L & [mouths "Loss"]. (.4) So, don't forget there is a change in \\
253 & & kine::tic energy. (.) Bear it in mind, (..) the initial kinetic \\
254 & & (..) energy (.4) given (.5) when the object was: (..) moving \\
255 & & at 4 meter per second, the answer is yes. 18KiloJoule. Ok, \\
256 & & (..) Coincidentally the answer for number 3, is 4.7. Now, \\
257 & number 6, ahh:: (.4) number 6 is also (..) really problematic. \\
258 & & \\
\hline
\end{tabular}




\section{c) SO ANYWAY}

An interesting and uncommon discourse markers found in LE (1). The researcher finds one combination of so and anyway which can be classified as a topic shift marker as well (line 367). The one and only so anyway can be found in LE (1). In line 367 the lecturer uses so anyway as a topic shift marker from a discussion of Newton's third law of motion to a digression part. In the digression part, she talks about her and the students' problem dealing with technology (lines 369-370). This part can be recognized from Data Sample 11 below.

Data Sample 11: LE (1)

\begin{tabular}{|c|c|c|}
\hline $\begin{array}{l}359 \\
360 \\
361\end{array}$ & $\mathrm{~L}$ & $\begin{array}{l}\text { different direction? (.5) What is the third law of motion? } \\
\text { Oh, sorry. What is Newton's third law of motion? For every } \\
\text { (gap)? }\end{array}$ \\
\hline 362 & $\mathrm{~S}$ & (mumbles) single movement. \\
\hline $\begin{array}{l}363 \\
364\end{array}$ & $\mathrm{~L}$ & $\begin{array}{l}\text { For every action (.3) there is a (..) equal (..) reaction. Right. } \\
\text { (..) But in different, direction. }\end{array}$ \\
\hline 365 & $\mathrm{~S}$ & \begin{tabular}{l|l} 
(In echo) & direction
\end{tabular} \\
\hline $\begin{array}{l}366 \\
367 \\
368 \\
369 \\
370 \\
371 \\
372 \\
373\end{array}$ & $\mathrm{~L}$ & $\begin{array}{l}\text { so there you are. I asked you whether you have learned it. } \\
\text { Yes, yes, yes. ((laughter)). So anyway, [moves back to po- } \\
\text { dium and laptop] emmm..(...) again I'm having problem. } \\
\text { Oh, You just see if you, are not so used to this technology, } \\
\text { you may have problem. I do not know how to move on (.7) } \\
\text { oh, ok, I use this. Ok. Now, do you, have his picture in your } \\
\text { book? [helds up a book] }\end{array}$ \\
\hline
\end{tabular}

From the findings of the use of macro marker in both LE (1) and LE (2), it can be concluded that the lecturer uses more rephraser in LE (1) than that of in LE (2). The lecturer uses 6 rephraser in LE (1) and only 5 in LE (2). It can also be concluded that the lecturer uses more topic shifter in LE (1) than that of in LE (2). The lecturer uses 8 topic shift marker in LE (1) and 5 in LE (2).

\section{Micro Markers}

In this section, the discussion is done based on classification of micro markers namely additional and causal (Chaudron and Richards 1986). These markers are fundamentally used as links to signal the internal or ideational relations within sentences so then the relations of one clause to another clause or one sentence to another sentence are easier to be compre- 
hended. Let us turn to the data and see the types of micro markers employed by the lecturer and to identify their function in the discourse. The following discussion will focus on additional and move on to causal.

\section{Additional Markers}

The data reveal that both LE (1) and LE (2) contain the following markers: and and or.

\section{a) $A N D$}

The findings show that and has been used as additional markers by the lecturer in both LE (1) and LE (2). In LE (1) and appears 9 times while in LE (2) it appears 3 times. In Data Sample 12 below the lecturer uses and to signal continuation of content, to signal two learning processes that must do exist (lines 274 and 275). and here is not merely an addition but a metastructure that links two very important concepts of learning the physical skills of calculating and the cognitive skill.

\section{Data Sample 12: LE (1)}

\begin{tabular}{|c|c|c|}
\hline $\begin{array}{l}267 \\
268\end{array}$ & $\mathrm{~L}$ & $\begin{array}{l}\text { Last one, (.3) what kind of representation that you need to } \\
\text { know }\end{array}$ \\
\hline 269 & $\mathrm{~S}$ & (..) Calculation \\
\hline $\begin{array}{l}270 \\
271\end{array}$ & $\mathrm{~L}$ & Not calculation. Calculation is an activity. [points 3 fingers] \\
\hline 272 & $\mathrm{~S}$ & (.6)Algebra \\
\hline $\begin{array}{l}273 \\
274 \\
275 \\
276 \\
277\end{array}$ & $\mathrm{~L}$ & $\begin{array}{l}\text { Algebraic of:: mathematical, representation:: of physi::cal } \\
\text { phenomena's. And now, you have to understand that (.) and } \\
\text { this is what, you can carry right through, until you finish } \\
\text { your education, and you don't stop there and we can use it } \\
\text { over and over again. }\end{array}$ \\
\hline
\end{tabular}

In Data Sample 13 below the lecturer talks about previous lecture topics which cover average speed, average velocity, and average acceleration. In lines 391, 392, and 395 and markers are used for adding the ideas.

\section{Data Sample 13: LE (1)}

\begin{tabular}{|l|l|}
\hline 388 & development of calculus (/).If you still remember, in the last \\
389 & 2 lectures we were: learning about (/) average speed, average \\
390 & velocity, average acceleration. Yeah. And you move on to \\
391 & instantaneous (..) speed, instantaneous (.) acceleration. And I \\
392 & told you that, yes, (/) in terms of average speed, and average \\
393 & acceleration. you can make use of the graphs: to \\
\hline
\end{tabular}




\begin{tabular}{|l|l|l|}
\hline \multicolumn{2}{|l|}{ Data continued } & \\
\hline 394 & & determine the $\mathrm{x} / \mathrm{dt}$ or $\mathrm{dv} / \mathrm{dt}$ and, how you move on (/) to \\
395 & change it into (.3) the differential expression dy by dx, ah.. I \\
396 & mean dy by dt or dx by dt (..) as well as \\
397 & & \\
\hline
\end{tabular}

Further, in LE (2) the lecturer also uses and which has a similar function to LE (1). In line 431 and functions to show a continuation of ideas, a continuation from the $\mathrm{x}$-axis, then, she moves on and talks about the $\mathrm{y}$-axis. This part can be recognized from Data Sample 14 below.

\section{Data Sample 14: LE (2)}

\begin{tabular}{|l|l|l|}
\hline 429 & L & Would you consider that or here? [no response from stu- \\
430 & & dents]. Right, so look. Here will be the x-axis [points and \\
431 & & moves along the front row]. And here will be the y-axis. \\
432 & & [points to the stairs in the centre of the dewan.] \\
433 & & \\
\hline
\end{tabular}

b) $O R$

The findings reveal that or marker has been used as markers to show a contrast of two things. Or is used only twice by the lecturer in LE (1) and none at all in LE (2). Or is used by the lecturer while she was exploring the change of state of motion or velocity (lines 450-453). She emphasizes on accelerating or decelerating as 'Applied some kind of force onto the moving object' (lines 457-458). Here or functions to signal the polar differences (line 455). This part can be recognized from Data Sample 15 below.

\section{Data Sample 15: LE (1)}

\begin{tabular}{|c|c|c|}
\hline $\begin{array}{l}439 \\
440 \\
441 \\
442 \\
443 \\
444 \\
445 \\
446 \\
447 \\
448 \\
449 \\
450 \\
451 \\
452\end{array}$ & L & $\begin{array}{l}\text { No, you are not. So, there you are, this is what is meant (..) } \\
\text { by net forces is zero. There are forces acting, but the } \\
\text { e:ffec:ti:ve (/).(.5) I'm using the word effective force [em- } \\
\text { phasis on effective and zero] is zero (hh). You sum up the } \\
\text { vertical. Ok. Downward and upward, the result then be- } \\
\text { comes? Zero.(hh) So, that is the reason why, you are (..) } \\
\text { where you are. (..)I am where, I am, right now. (..)Ok, so, } \\
\text { here it says [refers to slide] forces are what causes any (/) } \\
\text { change in the ve:lo:city, (.5) now in the past. (.3) I think, } \\
\text { this is one of the first time (.hh) I look at that, yeah. It just } \\
\text { says, forces are what causes change in the (/) state:.: of mo- } \\
\text { tion. Right. state of motion. Now, the state of motion is now } \\
\text { being change, they use the word ve::lo:city. (.3) If you } \\
\text { change }(/) \text { the velocity of a moving object, (..) that means }\end{array}$ \\
\hline
\end{tabular}




\begin{tabular}{|l|l|l|}
\hline \multicolumn{2}{|l|}{ Data continued } & \\
\hline 453 & & you are either acc::elerating it, (.5) you follow me? Or you \\
454 & & are de:celerating it. (.3)What does that mean? You have \\
455 & applied some kind of force, onto the moving object in order \\
456 & to, make it move faster or slower. Ok, now number 2, (.) so \\
457 & & there you are a force is that which causes an acceleration: \\
458 & (..) is moving slower, \\
459 & - considered acceleration as well?(/) \\
460 & & \\
461 & & \\
\hline
\end{tabular}

\section{Causal Markers}

This section will discuss because as a marker of causality. Because as a marker can be found both in LE (1) and LE (2).

\section{a) BECAUSE}

The findings show that because has been used as causal markers in both LE (1) and LE (2). In LE (1) because is used 6 times while in LE (2) it is used 10 times. Because is used in line 127 in order to show relationship of the slow motion of the lecturer relative or compared to that of the students on the escalator. She said the reason is because the escalator was going up and she was going down (lines 127-129). This part can be seen from Data Sample 16 below.

\section{Data Sample 16: LE (1)}

\begin{tabular}{|c|c|c|}
\hline $\begin{array}{l}110 \\
111 \\
112 \\
113\end{array}$ & & $\begin{array}{l}\text { So, the escalator is moving [hand movement upwards] this } \\
\text { way (..) and [L moves up the stairs] I'm (/) moving this way } \\
\text { too. What will be, the speed that you see me? (/) }\end{array}$ \\
\hline 114 & $\mathrm{~S}$ & (inaudible response) \\
\hline $\begin{array}{l}115 \\
116 \\
\end{array}$ & $\bar{L}$ & $\begin{array}{l}\text { [repeats answer by student] Faster? That means, (/) I have to } \\
\text { add? (..) my speed and }\end{array}$ \\
\hline 117 & $\mathrm{~S}$ & the speed of the escalator. \\
\hline 118 & $\mathrm{~L}$ & The speed of the escalator. \\
\hline $\begin{array}{l}119 \\
120 \\
121\end{array}$ & & $\begin{array}{l}\text { However, (.) if I'm going downward, and escalator is going } \\
\text { upward, (..) what (/), is my speed (.) relative to } \\
\text { You? }\end{array}$ \\
\hline 122 & $S$ & slow (.4) \\
\hline 123 & $\mathrm{~L}$ & Am I (.hh) moving faster or slower? \\
\hline 124 & $\mathrm{~S}$ & slower [all together] \\
\hline 125 & $\mathrm{~L}$ & why? \\
\hline
\end{tabular}




\begin{tabular}{|l|l|l|}
\hline \multicolumn{2}{|l|}{ Data continued } \\
\hline 126 & S & Inaudible response \\
\hline 127 & L & Because (/) the escalator is going up (..) but I'm going? (/) \\
128 & & \\
\hline 129 & S & Down \\
\hline
\end{tabular}

In Data Sample 17 below because which has been used to show reasons or justification can also be seen in lines 539 and 541 . Here because is used to justify the presence of evidence of gravitational forces and the difficulties in observing electromagnetic forces.

\section{Data Sample 17: LE (1)}

\begin{tabular}{|c|c|c|}
\hline $\begin{array}{l}535 \\
536 \\
537 \\
538 \\
539 \\
540 \\
541 \\
542\end{array}$ & $\mathrm{~L}$ & $\begin{array}{l}\text { around and give me the examples. Now, (..)so, (..) personal- } \\
\text { ly, it will be easier, for you to understand (hh) forces that } \\
\text { involve contact as oppose to the field forces. It is easier for } \\
\text { (..) you to manage: (/) problems that relate to gravitational } \\
\text { forces (.) because you can actually see: things happening, but } \\
\text { more (..) difficult will be the electromagnetic forces because } \\
\text { it sort of more abstract especially, when you are going to talk } \\
\text { about object or material at the atomic molecular level. }\end{array}$ \\
\hline
\end{tabular}

In Data Sample 18 below because markers which have similar function to that of in LE (1) are also used by the lecturer in LE (2). In lines 257 and 280 the lecturer was exploring question number 6 of the quiz which is problematic. Here, because marker is used (line 273) to show a reason why she did not agree with some of the students' answer which equal potential and kinetic energy (line 272-273). She said that 'In this case when this work done, the work done on both the object as well as the spring. So, the body increases the kinetic energy while the spring increases its potential energy. It means that the work done is used to increase the kinetic energy and also the potential energy' (lines 273-279).

Data Sample 18: LE (2)

\begin{tabular}{|l|l|l|}
\hline 257 & L & answer for number 3, is 4.7. Now, number 6, ahh:: (.4) \\
258 & & number 6 is also (..) really problematic. (.15) I have all \\
259 & & kinds of answer (/). But, basically: it is principal: of: con- \\
260 & & servation: of: energy:. Now, how are you going to (..) un- \\
261 & & derstand this. Ok, you have here a spring. [demonstrates \\
262 & & question number 6 with a marker and duster]. Look at this. \\
263 & & It is a solid. A spring here, now what do you do (/)? You \\
264 & & apply a force (..). When you apply a force, (..) the body \\
\hline
\end{tabular}




\begin{tabular}{|c|c|}
\hline \multicolumn{2}{|c|}{ Data continued } \\
\hline 265 & moves (/). Ok, (..) we have just discuss. (..) When work is \\
\hline 266 & done on the body (..) the body gains, (/) what? (/) kinetic \\
\hline 267 & energy. Don't forget, (..) there is this spring. What happen \\
\hline 268 & to the spring $(/)$ ? What happen when you pull the spring $(/)$ ? \\
\hline 269 & It extends::. So the potential energy increases. Now, what is \\
\hline 270 & it that you all did? Some of you said, ok (..), the: potential \\
\hline 271 & energy equals the kinetic energy. I would not accept it be- \\
\hline 272 & cause in this case when this (..) work done, the work done \\
\hline 273 & on both the object:: as well as the spring. So, the body (..) \\
\hline 274 & increases the kinetic energy while the spring increases its \\
\hline 275 & pot::ential energy. So, that means the work done (..) is used \\
\hline 276 & to increase the kinetic energy and also the potential energy. \\
\hline 277 & (..) So, that is the principle of conservation:: of energy. \\
\hline 278 & Probably this question is a \\
\hline 279 & \\
\hline 280 & \\
\hline
\end{tabular}

From the findings of the use of micro marker in both LE (1) and LE (2), it can be concluded that the lecturer uses more additional marker in LE (1) than that of in LE (2). The lecturer uses additional marker eleven times in LE (1) and only three times in LE (2). Meanwhile, it can also be concluded that the lecturer uses more causal marker in LE (2) than that of in LE (1). The lecturer uses causal marker ten times in LE (2) and only six times in LE (1).

\section{CONCLUSIONS AND SUGGESTIONS}

From the findings, it is revealed that there are three kinds of rephraser namely that means, I mean, and which means to say that. These markers functions to rephrase the preceding statement/a series of exchanges, to correct the previous statement, and to reformulate the prior statements. It is also identified that there are also three kinds of topic shifter namely so, now, and so anyway. These markers function to indicate a shift from one sub-topic to another sub-topic within the discourse. Here, the researcher also finds two kinds of additional markers namely and and so. These markers function to signal a continuation of content, to add ideas, and to show a contrast. It is also revealed that there is only one kind of causal marker namely because which function to demonstrate causalities.

Further, from the findings it can also be acknowledged that the lecturer uses more micro markers than macro markers. There are 30 micro markers 
and 24 macro markers. From those markers, causal markers are used the most by the lecturer (16 times), followed by additional markers (14 times), topic shifter (13 times), and rephraser (11 times).

In terms of types and functions of markers, the findings of this research are relevant with Chaudron and Richards (1986) and Fortuno (2006). Chaudron and Richards (1986) say that discourse markers are to signal a continuation and transition of idea, a shift of topic/sub-topic, causalities, a clarification of idea, etc, Fortuno (2006) finds similar types markers as the researcher finds in this research. However, a marker so anyway cannot be found in Fortuno (2006) and it becomes an interesting finding.

There is, indeed, a potential in this area for further research. The same research can be repeated with larger corpus so then there will be richer data to be analyzed further. In addition, more interpersonal interactive features (e.g. aside and digression) can enrich the micro analysis of a lecture. This research can also be compared to NNS of English lectures from different disciplines (in engineering or medicine for examples) or can be contrasted to native of English lecture (in the United States for example). Further, since this research only employs qualitative method, collaborating quantitative and qualitative research can enrich the data and give an added-value for the findings as well. There is always room for improvement in expanding this research.

\section{REFERENCES}

Camicciottoli, Crawford B. 2004. Interactive Discourse Structuring in L2 Guest Lectures: Some Insights from a Comparative Corpus-Based Study. Journal of English for Academic Purposes 3: 39-54.

Chaudron, C \&Richards, J. C. 1986. The Effect of Discourse Markers on the Comprehension of Lectures. Applied Linguistics 7 (2): 113-127.

Clarke, A. \& Dawson, R. 1999. Evaluation Research. London: Sage Publications.

Flowerdew, J \& Miller, L. 1996. Lectures in a Second Language: Notes towards a Cultural Grammar. English for Specific Purposes 15 (2): 121-140.

Fortuno, B.B. 2006. Discourse Markers within the University Genre: A Contrastive Study Between Spanish and North American Lectures. Unpublished Dissertation. English Studies Department, Humanities and Social Sciences Faculty, Universitat Jaume. 
Morell, T. 2000. EFL Content Lectures: A Discourse Analysis of an Interactive and Non-Interactive Style. Spain: Departemento de Filologia Inglesia, Universidad de Alicante (working papers, 7).

Olsen, L. A \& Huckin, T. N. 1990. Point-Driven Understanding in Engineering Lecture Comprehension. English for Specific Purposes 9: 3347.

Schiffrin, D. 1987. Discourse Markers. New York: Cambridge University Press.

Yang Xue-qian. 2007. The Influence of Discourse Organizational Patterns on Chinese EFL Learners' Listening Comprehension. US-China Foreign Language 5 (3): 22-31.

Young, L. 1994. University Lectures Macro-Structure and Micro Features. In Flowerdew, J (Ed.). Academic Listening: Research Perspective. Cambridge: Cambridge University Press. pp. 159-176. 